\title{
A TRAJETÓRIA DO CANTEIRO DE OBRA NAS INTERVENÇÕES HABITACIONAIS DO SÉCULO XX
}

\author{
Heloisa Nunes e Silva \\ Universidade Federal de Santa Catarina - UFSC / Instituto Federal de Santa Catarina -IFSC \\ Orientador: Juan Antonio Zapatel Pereira de Araújo \\ heloisa.nunes@ifsc.edu.br
}

\section{RESUMO}

Este estudo auxilia no entendimento da trajetória evolutiva do espaço do canteiro de obras à luz das intervenções habitacionais em cidades do século XX, fomentando à pesquisa sobre a cultura de projeto do espaço do canteiro de obras. Realizou-se uma pesquisa documental comparativa entre projetos de habitação selecionados pelo seu caráter de relevância do contexto de projeto da edificação e em distintos períodos urbanos de cidade, possibilitando contextualizar seus reflexos sobre a organização espacial do canteiro de obras. Construíram-se, a partir disso, seis panoramas da evolução espacial do canteiro de obras, estruturado por critérios de instruções normativas, organização espacial, relações de vizinhança, impactos urbanos e identidade social do homem. A espacialização do canteiro de obras foi moldada à medida das transformações no modo de organizar as habitações nas cidades, inclusive sob o aspecto organizacional da cadeia produtiva da construção civil, e da forma de adaptar-se às necessidades do homem-operário.

Palavras chave: intervenção urbana, projeto de habitação, canteiro de obras

\begin{abstract}
This study assists in the understanding of the evolutionary trajectory of the construction site space by the housing interventions in cities of the twentieth century, fomenting to the research on the design culture of the construction site space. A comparative documentary research was carried out between housing projects selected for their relevance in the context of the building project and in different urban periods of the city, making it possible to contextualize their reflections on the spatial organization of the construction site. From this, six scenarios of the construction site spatial evolution were constructed, structured by criteria of normative instructions, spatial organization, neighborhood relations, urban impacts and the man social identity. The construction site spatialization was shaped by the transformations in the way of organizing housing in cities, including the organizational aspect of the productive chain of civil construction, and the way of adapting to the needs of the worker.
\end{abstract}

Key words: urban intervention, housing project, construction site 


\section{INTRODUÇÃO}

O ciclo do processo da construção de edifícios é complexo e envolve diversas etapas, como de definição do terreno, do projeto da edificação, da execução da edificação. Neste ciclo, a etapa de execução da edificação engloba também a materialização do canteiro de obras, que se caracteriza como um ambiente de trabalho sazonal e com diversas atividades além da de produção, entre elas a de moradia, de lazer, de convívio social, de aprendizado, de circulação. Observa-se que o canteiro de obra costuma ser desfavorecido de investimentos materiais e financeiros, pelo seu fator de transitoriedade. Os reflexos dessa prática afetam negativamente às condições de habitabilidade e na adequação das áreas de trabalho do canteiro de obras. No Brasil, as pesquisas de Saurin \& Formoso (2006) apontam que o planejamento do espaço do canteiro de obras tem sido negligenciado no gerenciamento da construção, sendo as decisões tomadas à medida que os problemas surgem, no decorrer da execução. Disso, resultam em condições insalubres de trabalho, representando danos à saúde do homem-operário e, numa escala maior, à sociedade de qualquer país.

Ao se relacionar a trajetória do espaço do canteiro de obras com as formas de intervenção habitacional do século XX em alguns países da Europa e da América do Sul, identificam-se que, à sua época, as mudanças na sociedade e na política habitacional ocasionaram (re)organizações urbanas, as quais também influenciaram diretamente na forma como se estruturava o espaço de produção do edifício, isto é o canteiro de obras, conforme ilustra a imagem 1.

As pesquisas de Zapatel (2013: 13) acerca das intervenções urbanas e de habitação nas cidades do século XX apontam "estratégias de projeto e os processos de revitalização urbana que, tanto em soluções de integração à morfologia existente como de inovação tipológica, exemplificam formas de (re)constituição urbana", diante de demandas de crescimento habitacional nas cidades. $\mathrm{O}$ autor relacionou alguns projetos de habitação na Europa, devido à relevância da proposta conceitual à época, e realizou estudos sobre o processo de projetar a edificação de modo a estabelecer uma linha norteadora sobre o processo de projeto de habitação no século $X X$, em que a sua leitura permite estabelecer uma lógica de projeto baseada na continuidade de experiências habitacionais e na diferenciação do conjunto pelas estratégias inovadoras a seu tempo. Deste modo, os projetos analisados por Zapatel são a base para este artigo, conforme quadro 2.

Portanto, a pesquisa inicia-se no período pós-1gue rra mundial em Viena/Aústria nas habitações coletivas dos Hofs nos anos de 1920. Após, segue para o modelo habitacional do Siedlung em Frankfurt/Alemanha nos anos de 1930, depois para o modelo da cidade planejada em Brasília/Brasil nos anos de 1950, em seguida para o conjunto habitacional na cidade histórica de Évora/Portugal nos anos de 1970, depois se estuda a intervenção urbana no bairro de Gràcia em Barcelona/ Espanha nos anos de 1980. A presente pesquisa tenta relacionar um novo olhar nesta relação entre intervenção habitacional e o espaço do canteiro de obras, de modo induzir a uma prospecção do espaço da "cidade canteiro de obras" e permitir uma reflexão ampla sobre o tema da trajetória do espaço do canteiro de obras pelo olhar do arquiteto. Para contextualizar essa discussão, é utilizado o exemplo da Usina Hidrelétrica de Belo Monte em Altamira/Brasil nos anos de 2016.

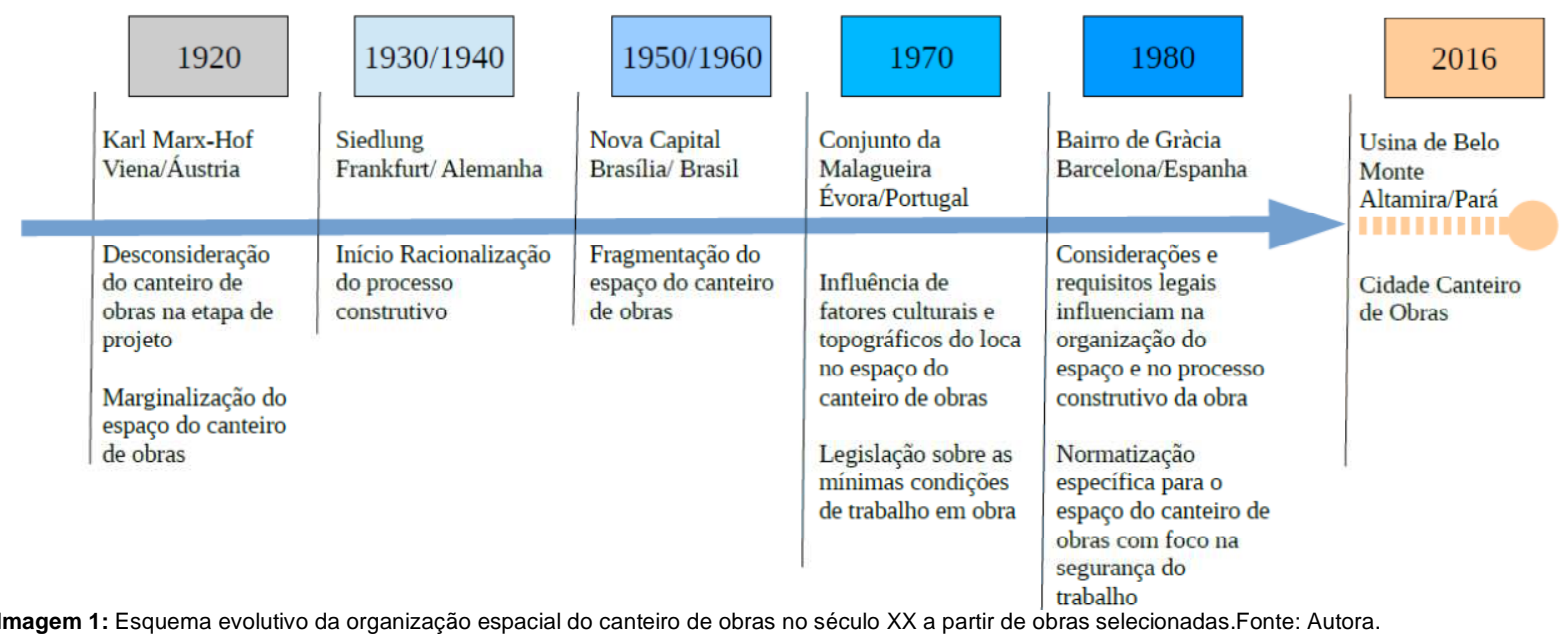

Imagem 1: Esquema evolutivo da organização espacial do canteiro de obras no século XX a partir de obras selecionadas.Fonte: Autora. 


\section{MÉTODO DE PESQUISA}

Este trabalho está estruturado em pesquisa documental e de imagens para cada um dos recortes históricos, em seguida realiza-se uma análise baseada em multicritérios (instruções normativas, organização espacial, relações de vizinhança, impactos urbanos e identidade social do homem), resultando num quadro histórico do processo de organização do espaço do canteiro de obras em meio as diferentes formas de intervenção habitacional do século XX. O critério de escolha dos projetos destacados em cada recorte histórico é devido à peculiaridade de tipologia e da morfologia do projeto e a sua contribuição na cultura de projeto em arquitetura e urbanismo, conforme discute Zapatel (2013).

Também foi realizado um recorte na atualidade para uma obra de porte relevante no Brasil, de modo a embasar a discussão sobre a confluência do espaço do canteiro de obras com a cidade, até mesmo, tornando-se uma única entidade.

Em cada recorte histórico podem ser verificadas características políticas, socioculturais, tecnológicas e de projeto dos espaços dos canteiros de obras, refletindo na habitabilidade do espaço construído, na qualidade de vida no trabalho e na urbanidade da cidade.

\section{O CANTEIRO DE OBRAS PELO OLHAR ARQUITETÔNICO}

O "olhar arquitetônico" sobre o canteiro de obras já é tratado por Sérgio Ferro desde a década de 1970 no seu livro O Canteiro e o Desenho, cuja crítica aborda, entre outros aspectos, as condições de trabalho dos operários da construção civil nos canteiros e as relacionas com a atuação dos profissionais arquitetos e engenheiros, emergindo temas de irracionalidade do projeto, relações de dominação na produção, vestígio da arte e da estética na obra.

A arquitetura e a engenharia podem ser compreendidas como ciências que desenvolvem espaços considerando condições de estética, técnica, construtividade e de utilização. Benévolo em 1976 discorria sobre o tema e afirmava que isto não diz respeito apenas à questão da qualidade ou aos processos técnicos de execução e multiplicação, mas sim à mediação entre qualidade e quantidade. Stroeter (1986) dizia que se deve compreendê-los como o processo mental que leva da concepção de um projeto até o resultando final em uma construção.

As pesquisas de Saurin \& Formoso (2006) demonstraram que o planejamento do canteiro tem sido um dos aspectos mais negligenciados no gerenciamento da construção, sendo as decisões tomadas à medida que os problemas surgem, no decorrer da execução. Em conseqüência, os canteiros de obra muitas vezes deixam a desejar em termos de organização e segurança, fazendo com que, longe de criar uma imagem positiva das empresas no mercado, acabem por recomendar certa "distância".

Assim, como em outros espaços de trabalho, o canteiro de obras requer atenção às suas condições de salubridade física e, de certa maneira, de ordem da psicologia ambiental. Moreno \& Mamede (2013) relatam estudos de como o sistema construtivo em obras civis no Brasil, ainda é feito de maneira precária, com atrasos em obras, desperdício de materiais, falha no planejamento e condições subumanas de trabalho dentro dos canteiros de obra.

O espaço habitado pelo homem requer condições mínimas para torná-lo habitável, isto é, a habitabilidade do ambiente, cujo termo abrange além da unidade física da edificação as faces coletivas e privadas, psicológicas, sociais e culturais do indivíduo que utiliza aquele espaço (De Sousa Araújo e Jacyntho, 2014). Ademais, outros aspectos interferem na qualidade do ambiente construído, tais como área edificada, divisões internas, instalações, infraestrutura de abastecimento de água, esgoto, drenagem, sistema viário (Bonduki, 2002).

Logo, pode-se assumir um olhar arquitetônico sobre o espaço do canteiro de obras, orientado para a elaboração, a construção e a urbanização dos espaços, observando fatores que devem contribuir para melhorar as condições de vida do homem de hoje e de suas futuras gerações (Silva, 2014).

No Brasil, o espaço do canteiro de obras pode ser projetado juntamente ao documento existente no Programa de Condições e Meio Ambiente de Trabalho na Indústria da Construção - PCMAT (Norma 
Regulamentadora - 18, Portaria 3.214 do MTE, 1978), integrando, assim, um documento único contendo o projeto evolutivo do canteiro de obras, sintetizando três perspectivas necessárias: 1) segurança do trabalho, 2) logística de produção e 3) urbanidade e habitabilidade(Silva, 2014). O impacto dessa boa relação está na melhoria da condição de ambiente de trabalho e de vivência no canteiro de obras aliada à produtividade e, para a sociedade, reflete no respeito da condição de urbanidade ao preservar as funções de mobilidade da cidade.

\subsection{ESPAÇOS DO CANTEIRO DE OBRAS}

A norma brasileira ABNT NBR 12.284 (1991) define canteiro de obras como "áreas destinadas à execução e apoio dos trabalhos da indústria da construção, dividindo-se em áreas operacionais e áreas de vivência". A elaboração do projeto do canteiro de obra deve estar sob responsabilidade da equipe de engenharia e arquitetura das empresas, devendo ser aprovado pelo corpo técnico da empresa antes da sua implantação no terreno, a fim de evitar rearranjos físicos futuros e situações técnicas problemáticas.

Ferreira (1998) apresenta alguns princípios gerais que o projeto do canteiro de obras pode evidenciar, tais como reduzir, minimizar ou eliminar as perdas, assim como as considerações sobre a determinação da localização dos elementos no canteiro, como acessos, almoxarifado, escritório, banheiro, refeitório, etc. O terreno também influenciará nas instalações a ser construídas. $O$ autor sinaliza que o arranjo físico do canteiro deve ser elaborado com o objetivo de aperfeiçoar o seu funcionamento global, considerando a capacidade efetiva da obra, a segurança das instalações e a produtividade das operações. Após a definição do arranjo físico das diversas fases do canteiro, deve-se realizar o detalhamento dos elementos, com a divisão funcional dos ambientes e a localização de móveis, máquinas e equipamentos, de modo a otimizar os fluxos dos processos, reduzir perdas, evitar interferências e aproximar as atividades que têm maior grau de inter-relações.

No Brasil, a Norma Regulamentadora - 18 (Portaria 3.214 do MTE, 1978) trata sobre as "Condições e meio ambiente de trabalho na Indústria da Construção, estabelecendo diretrizes de ordem administrativa, de planejamento e de organização, que objetivam a implementação de medidas de controle e sistemas preventivos de segurança nos processos, nas condições e no meio ambiente de trabalho". A norma apresenta uma lista de ambientes e de condições mínimos relacionados aos espaços de convivência do trabalhador, a saber: instalações sanitárias, vestiário, alojamento, local de refeições, cozinha - quando houver preparo de refeições, lavanderia, área de lazer, ambulatório. O mesmo é apresentado para os espaços de produção, tais como: área de carpintaria, armações de aço, produção de concreto, soldagem, entre outros. Cada ambiente possui requisitos específicos, conforme é visto no quadro 1.

\begin{tabular}{|c|l|}
\hline Ambiente & \multicolumn{1}{c|}{ Requisitos construtivos pela NR-18 } \\
\hline \multirow{5}{*}{ Vestiário } & a) ter paredes de alvenaria, madeira ou material equivalente; \\
& $\begin{array}{l}\text { b) ter pisos de concreto, cimentado, madeira ou material equivalente; } \\
\text { c) ter cobertura que proteja contra as intempéries; }\end{array}$ \\
d) ter área de ventilação correspondente a 1/10 (um décimo) de área do piso; \\
e) ter iluminação natural e/ou artificial; \\
f) ter armários individuais dotados de fechadura ou dispositivo com cadeado; \\
g) ter pé-direito mínimo de 2,50m (dois metros e cinqüenta centímetros), ou respeitando-se o \\
que determina o Código de Obras do Município, da obra; \\
\\
$\begin{array}{l}\text { h)ser mantidos em perfeito estado de conservação, higiene e limpeza; } \\
\text { i)ter bancos em número suficiente para atender aos usuários, com largura mínima de 0,30m } \\
\text { (trinta centímetros). }\end{array}$ \\
\hline Carpintaria & $\begin{array}{l}\text { A carpintaria deve ter piso resistente, nivelado e antiderrapante, com cobertura capaz de } \\
\text { proteger os trabalhadores contra quedas de materiais e intempéries }\end{array}$ \\
\hline
\end{tabular}

Quadro 1- Exemplo de requisitos da NR18 para os ambientes do canteiro de obras

Fonte: Adaptado de Portaria 3.214 do MTE (1978)

\subsection{INTERVENÇÕES HABITACIONAIS REFERENCIAIS}

Uma leitura do cenário social e político sobre as intervenções habitacionais destacadas dos estudos de Zapatel(2013) permitem uma contextualização histórica sobre a relação da cidade $x$ canteiro de obras orientada até a atualidade. No período pós-guerra, as cidades europeias estavam com sua estrutura de cidade devastada: sem condições de funcionamento de estruturas básicas, sem moradias habitáveis, sem oportunidade de empregos. Aos poucos se foi reorganizando no aspecto econômico, possibilitando as 
adequações urbanísticas e de expansão territorial. Neste período, a reconstrução da cidade era em tal proporção que houve uma simbiose entre cidade e canteiro de obras. Á medida que se organizou a cidade, o canteiro de obras deslocou-se para a periferia para poder dar vazão aos projeto habitacionais coletivos e de delimitação da expansão urbana. Tornou-se um espaço compartilhado entre obra em construção e sítio na periferia, não havendo delimitações físicas, como muros, entre espaço da obra e espaço público (bairro, rua). A tecnologia construtiva era tradicional, com emprego de mão de obra extensiva e de incipiente organização espacial. Ver imagem 2.

As cidades europeias se consolidaram em franca expansão econômica e urbana, havendo a aglutinação de diversas atividades na cidade aliada à crescente necessidade do automóvel para os grandes descolamentos entre as áreas da cidade, que se transformaram em metrópoles. As novas demandas habitacionais se organizaram segundo a ótica de qualidade de vida em que o caráter bucólico e de tipologia de habitação de pavimento baixo, estabeleceu-se um novo conceito urbanístico: a cidade-jardim. A indústria evoluída possibilitava uso de componentes industrializados, que agilizavam as construções das edificações. Deste modo o espaço do canteiro de obra sofreu mudanças: a adoção do processo de industrialização da construção, a inserção de máquinas e equipamentos auxiliares no transporte de componentes e materiais pré-fabricados, a diminuição do número de operários, a especialização das funções em obra, o início da organização espacial do canteiro de obras segundo a necessidade de produção de componentes, de máquinas e guarda de materiais no local da obra.

No caso de uma cidade inteira nova e planejada, como Brasília/Brasil, o canteiro de obras necessitou ser fragmentado em área de produção de edifícios e área de abrigo aos trabalhadores da obra, sendo estes geralmente espaços auto-organizados por necessidade. Ao passo que a cidade nova teve as obras finalizadas, alguns desses espaços do canteiro de obras se mantiveram no local, evoluindo para bairros ou novas cidades.
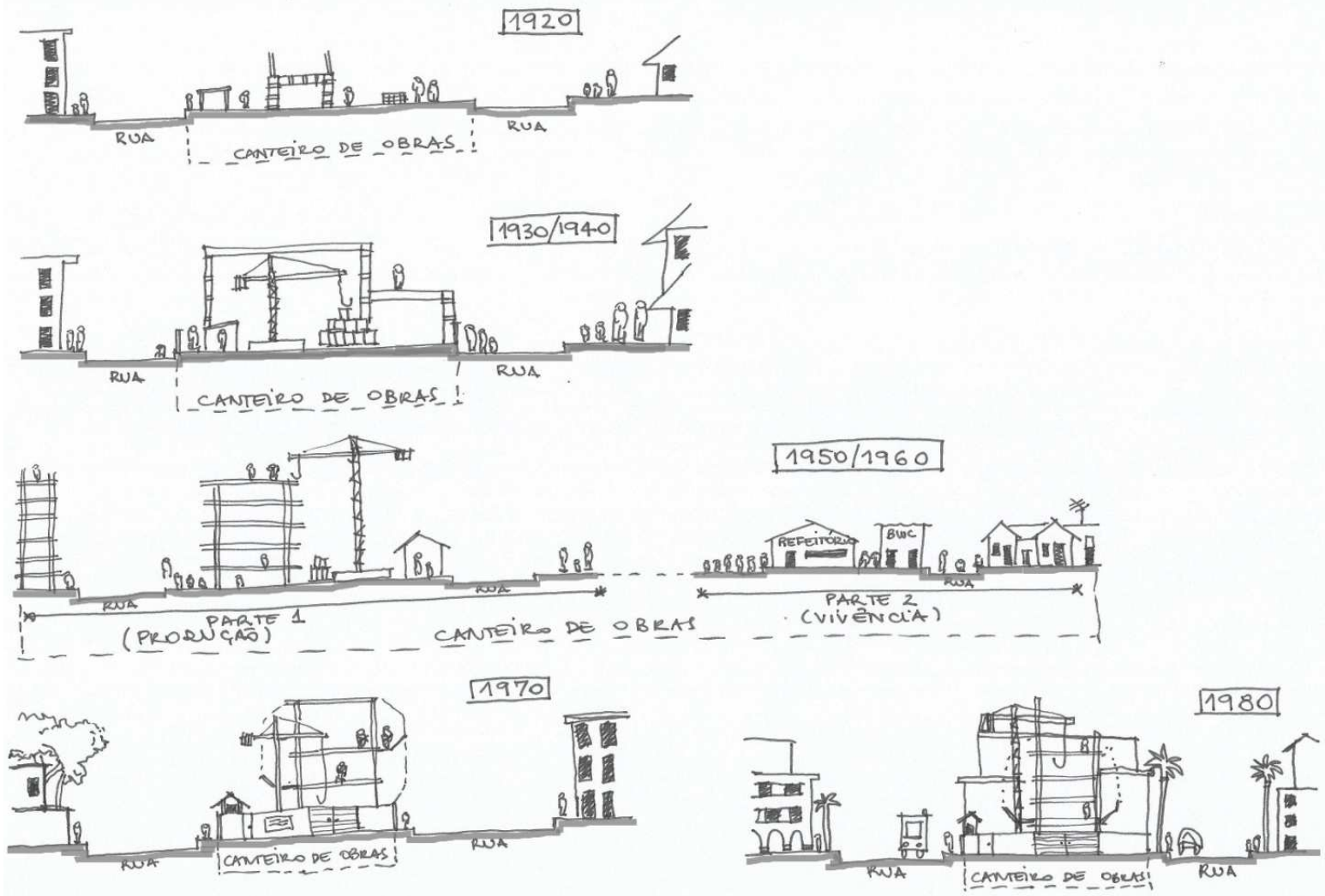

Imagem 2: llustrações da relação do espaço do canteiro de obras ao longo do século XX, destaque da relação entre canteiro de obras(privado) $x$ rua (público) .

Fonte: Autora. 


\begin{tabular}{|c|c|c|c|c|c|}
\hline & 1920 & 1930 & 1950 & 1970 & 1980 \\
\hline $\begin{array}{l}\text { Intervenção } \\
\text { analisada }\end{array}$ & $\begin{array}{l}\text { Hof } \\
\text { Viena /Áustria }\end{array}$ & $\begin{array}{l}\text { Siedlung } \\
\text { Frankfurt/Alema- } \\
\text { nha }\end{array}$ & $\begin{array}{l}\text { Brasília } \\
\text { Brasília/Brasil }\end{array}$ & $\begin{array}{l}\text { Malagueira } \\
\text { Évora/Portugal }\end{array}$ & $\begin{array}{l}\text { Grácia } \\
\text { Barcelona/Espanha }\end{array}$ \\
\hline Modalidade & Habitação & Habitação & Cidade planejada & Habitação & Habitação \\
\hline $\begin{array}{l}\text { Cenário } \\
\text { político e } \\
\text { social da } \\
\text { época }\end{array}$ & $\begin{array}{l}\text {-O governo Austro- } \\
\text { Marxista, por meio } \\
\text { da taxação dos } \\
\text { industriários e da } \\
\text { desapropriação de } \\
\text { áreas da periferia, } \\
\text { viabilizou a } \\
\text { construção de } \\
\text { moradias sociais, } \\
\text { adotando a } \\
\text { linguagem imperial } \\
\text { como signo de } \\
\text { valorização da } \\
\text { classe operária. } \\
\text {-Período pós- } \\
\text { 1Guerra Mundial } \\
\text { na Europa } \\
\text { (reconstrução das } \\
\text { cidades) } \\
\text {-contratação de } \\
\text { operário para as } \\
\text { obras de modo } \\
\text { informal; } \\
\text {-carece de } \\
\text { legislação } \\
\text { específica para a } \\
\text { área de produção } \\
\text { do edifício, sendo } \\
\text { desconsiderada } \\
\text { da etapa de } \\
\text { projeto; }\end{array}$ & $\begin{array}{l}\text {-Proposta } \\
\text { intermediária } \\
\text { entre a cidade e } \\
\text { o campo, } \\
\text { baseado nos } \\
\text { ideários da } \\
\text { Cidade- Jardim, } \\
\text { na descentra- } \\
\text { lização urbana, } \\
\text { na visão de } \\
\text { salubridade } \\
\text { urbana; } \\
\text {-Industrialização } \\
\text { em expansão } \\
\text { - Social } \\
\text { Democracia } \\
\text { Cristã com a } \\
\text { visão da } \\
\text { habitação social } \\
\text { (da casa)como } \\
\text { valorização da } \\
\text { família proletária; }\end{array}$ & $\begin{array}{l}\text {-Cidade Racional- } \\
\text { funcionalista } \\
\text { (Trabalho, } \\
\text { Habitação, Lazer, } \\
\text { Circulação) } \\
\text { Cidade de } \\
\text { Representatividade } \\
\text { (Capital Federal) } \\
\text {-Releitura da } \\
\text { Cidade -jardim , } \\
\text { Hof e cidade } \\
\text { tradicional } \\
\text {-Projeto de cidade } \\
\text { nova com } \\
\text { zoneamento de } \\
\text { funções (Plano } \\
\text { Piloto- Lúcio Costa } \\
\text { 1957) } \\
\text {-vinda de operários } \\
\text { de todas as partes } \\
\text { do país; } \\
\text { - formalização } \\
\text { dos sindicatos da } \\
\text { construção civil } \\
\text { pelo Estado, no } \\
\text { intuito de } \\
\text { organizar } \\
\text { melhorias no } \\
\text { trabalho da } \\
\text { categoria }\end{array}$ & $\begin{array}{l}\text { - Transição política } \\
\text { da Ditadura para a } \\
\text { Democracia } \\
\text { - Programa de } \\
\text { Readequação } \\
\text { urbana da periferia } \\
\text { por meio do } \\
\text { Programa de Serviço } \\
\text { de Apoio } \\
\text { Ambulatorial Local } \\
\text { (SAAL); } \\
\text { - intervenção em } \\
\text { áreas periféricas e } \\
\text { improdutivas ( } \\
\text { quintas) } \\
\text { - fator do sincretismo } \\
\text { da cultura local no } \\
\text { projeto da } \\
\text { intervenção urbana } \\
\text { (relevo, tradições, } \\
\text { estética) } \\
\text { - racionalização do } \\
\text { projeto da } \\
\text { edificação } \\
\text { considerando as } \\
\text { ampliações futuras, } \\
\text { refletem no } \\
\text { processo } \\
\text { construtivo no fator } \\
\text { agilidade e controle } \\
\text { de materiais }\end{array}$ & $\begin{array}{l}\text {-Péssimas } \\
\text { condições urbanas } \\
\text { na periferia no final } \\
\text { do séc XIX e início } \\
\text { do Sec XX ( favelas, } \\
\text { falta infraestrutura } \\
\text { básica, escolas, } \\
\text { transporte, lazer) } \\
\text { - Movimento de } \\
\text { vizinhos a partir de } \\
\text { 1960 pela } \\
\text { demanda de } \\
\text { melhores } \\
\text { condições de vida } \\
\text { urbana } \\
\text {-Período pós a } \\
\text { ditadura do } \\
\text { Franquismo }\end{array}$ \\
\hline $\begin{array}{l}\text { Identidade } \\
\text { social do } \\
\text { homem }\end{array}$ & $\begin{array}{l}\text { - cultura do } \\
\text { "Homem-novo" } \\
\text { (Max Adler } \\
\text { "cidadão } \\
\text { consciente, } \\
\text { produtor, } \\
\text { comunitário", } \\
\text { mulher no mercado } \\
\text { de trabalho) }\end{array}$ & $\begin{array}{l}\text { - Resgate da } \\
\text { ideia da Família } \\
\text { como célula } \\
\text { social em respo- } \\
\text { sta ao cenário da } \\
\text { vida na Metró- } \\
\text { pole (diversidade, } \\
\text { aglomero, difu- } \\
\text { são do automó- } \\
\text { vel) }\end{array}$ & $\begin{array}{l}\text { - Homem Racional } \\
\text { (família moderna e } \\
\text { perfil de classe } \\
\text { média) } \\
\text { - para o canteiro } \\
\text { de obras oportu- } \\
\text { nidade de traba- } \\
\text { lho, riqueza e } \\
\text { ascensão social) }\end{array}$ & $\begin{array}{l}\text {-Homem em busca } \\
\text { de qualidade de } \\
\text { vida onde mora, } \\
\text { através de } \\
\text { transformações } \\
\text { urbanas } \\
\text { direcionadas pela } \\
\text { comunidade local. }\end{array}$ & $\begin{array}{l}\text { - Renovação urbana } \\
\text { para propiciar } \\
\text { melhor qualidade } \\
\text { de vida nos } \\
\text { centros urbanos } \\
\text { da grande cidade }\end{array}$ \\
\hline
\end{tabular}

Quadro 2: Contexto político a época da intervenção habitacional analisada.

Fonte: Autora.

\section{REFLEXOS NA ORGANIZAÇÃO DO ESPAÇO DO CANTEIRO DE OBRAS}

A experiência da organização normativa do espaço do canteiro de obras pode estar relacionada com as diversas formas de (re)estruturar as cidades a partir de intervenções habitacionais referenciadas do século XX, tratando questões como a habitabilidade do espaço construído, a segurança do trabalho e a urbanidade da cidade

\subsection{DÉCADA DE 1920: CANTEIRO DE OBRAS MARGINALIZADO}

A intervenção analisada foi o Karl Marx-Hof, de Karl Ehn, em Viena/Áustria, com 1.328 unidades habitacionais e localizado periferia da cidade.

A época, não havia registro oficial sobre uma instrução normativa aplicada ao canteiro de obras.

Pode-se verificar nas imagens da construção do Hof uma organização espacial do canteiro de obras com a indefinição de espaço entre área pública(vias, passeio) x privada(local da obra em si), há o trânsito irrestrito 
de pessoas dentro do espaço de produção do edifício, há construção aleatória das instalações de apoio à obra (sanitários, refeitório, escritório, central de produção, etc) e sem um padrão orientativo ou definição de condições mínimas de salubridade, a técnica construtiva era artesanal e de fácil manuseio (madeira, blocos cerâmicos, roldanas). Ver imagem 2 e 3.

As relações de vizinhança do canteiro de obras são diretas com as áreas circunvizinhas à obra, sem elemento construtivo como barreira de demarcação do espaço privado; as condições sanitárias precárias das cidades são replicadas no espaço do canteiro de obras.

Os impactos urbanos do canteiro de obras sobre a cidade/bairro remetem ao público operariado das obras que intensifica a circulação de veículos (caminhão, ônibus, carros, moto, bicicleta) nas ruas próximas, condições ambientais são alteradas pelo ruído e poeiras das atividades da construção civil, alterações de trajeto de vias ou passeios públicos para servirem de apoio às atividades da obra (carga e descarga).

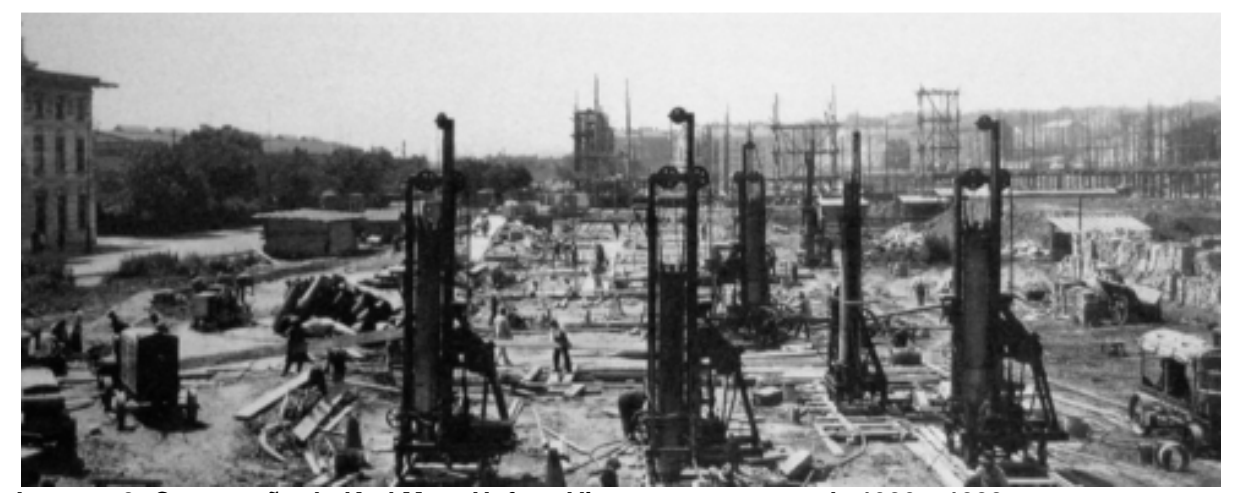

Imagem 3: Construção do Karl Marx-Hof em Viena entre os anos de 1926 a 1933.

Fonte: http://www.porr.at/index.php?id=623\&L=1

\subsection{DÉCADAS DE 1930/1940: INÍCIO DA RACIONALIZAÇÃO DO PROCESSO DE PROJETO DA EDIFICAÇÃO INFLUENCIOU NA PRÉ-ORGANIZAÇÃO ESPACIAL DO CANTEIRO DE OBRAS}

O modelo do Siedlung, de Ernst-May, em Frankfurt/Alemanha, com unidades habitacionais padronizadas e com pátio verde(quintal ou jardim) anexo à edificação, permite sintetizar a condição do espaço da obra neste período, o qual ainda mantém-se sem registro oficial de instrução normativa aplicada ao canteiro de obras.

Com o fato da crescente industrialização dos componentes e da racionalização do processo de projeto e da construção, observa-se que há alterações na organização espacial do canteiro de obras, em que há uma pré-organização do espaço da obra em local de produção in loco de componentes(blocos), em local de armazenamento e em local de instalação de equipamentos de obra. Ainda mantém-se a indefinição de espaços públicos x privado (canteiro de obras), bem como o trânsito irrestrito de pessoas dentro do espaço de produção do edifício. Há, ainda, a construção aleatória das instalações de apoio à obra (sanitários, refeitório, escritório, central de produções, etc), sem um padrão orientativo ou definição de condições mínimas de salubridade. A técnica construtiva encontrava-se em transição da artesanal e de fácil manuseio (madeira, blocos, roldanas) para a industrialização de componentes e uso de maquinários de grande porte (ex.: gruas). Ver imagem 2 e 4.

Sobre as relações de vizinhança do canteiro de obras, mantém-se a relação direta com as áreas circunvizinhas à obra, sem elemento construtivo como barreira de demarcação do espaço privado; as aplicações de soluções sanitárias nas intervenções habitacionais emergem pensamentos semelhantes para as condições sanitárias no espaço do canteiro de obras (higiene, esgoto), porém ainda se mantém algumas soluções sanitárias precárias no espaço do canteiro de obras (ex.:esgoto sem destinação adequada).

Os impactos urbanos do canteiro de obras na cidade/bairro ainda são do público operariado das obras intensifica a circulação de veículos (caminhão, ônibus, carros, moto, bicicleta) nas ruas próximas, das condições ambientais alteradas pelo ruído e poeiras das atividades da construção civil, das alterações de trajeto de vias ou passeios públicos para servirem de apoio às atividades da obra (carga e descarga). Verifica-se a crescente especialização das tarefas em obra, resultado da organização da área de produção e da industrialização do processo construtivo. 


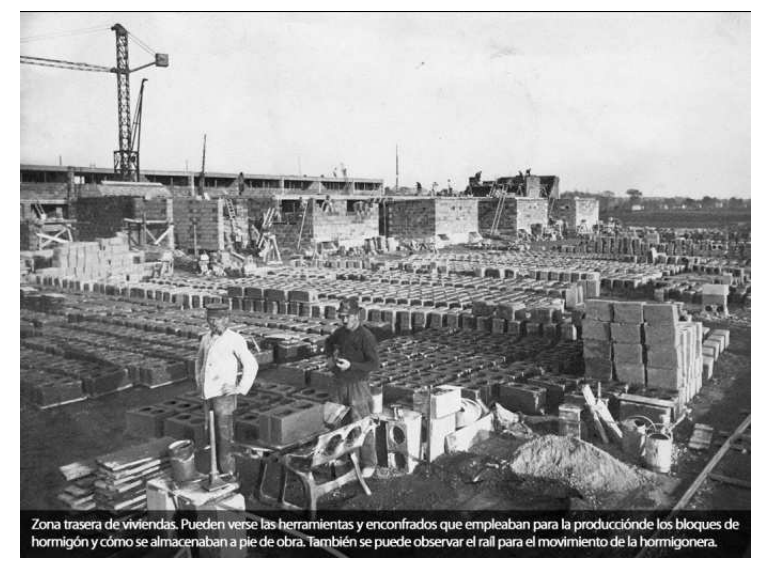

Imagem 4: Construção das Siedlungs na Alemanha com os componentes industrializados no canteiro de obras. Fonte: http://www.industrializedarchitecture.com/gropiussiedlung-torten.html

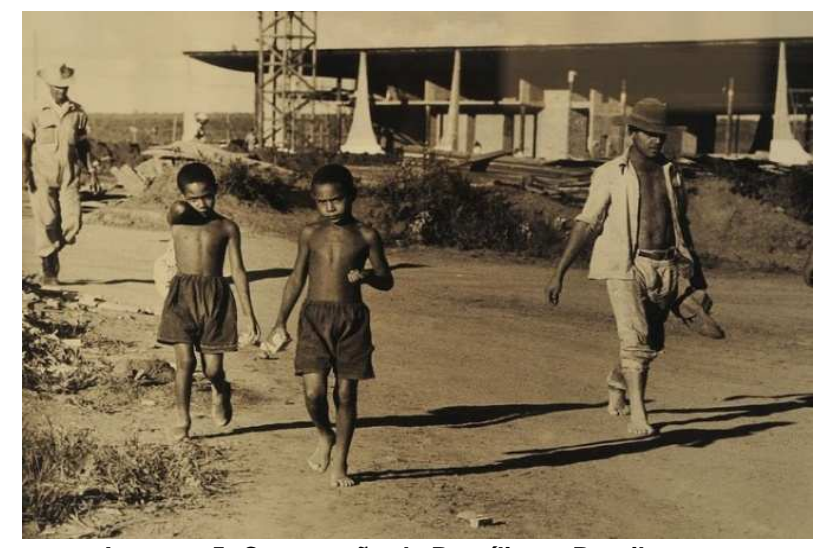

Imagem 5: Construção de Brasília no Brasil e os candangos(trabalhadores da obra) adultos e crianças. Fonte: Foto: Arquivo Público do DF

\subsection{DÉCADAS DE 1950/1960: FRAGMENTAÇÃO NO ESPAÇO DO CANTEIRO DE OBRAS}

A construção da nova capital do Brasil em Brasília/ DF, permite expandir a relação de importância do espaço de produção do edifício para a estruturação das cidades.

No período da obra da capital também se encontrava sem registro oficial de instrução normativa aplicada ao canteiro de obras. Havia a regulação do contrato de trabalho regido pela Consolidação das Leis Trabalhista (CLT) de 1943. Ver imagem 2 e 5.

$\mathrm{Na}$ organização espacial do canteiro de obras, a empresa construtora o fragmenta em local para construção de Brasília e outro local para abrigar os operários fora do espaço de construção da obra em si, ha uma préorganização do espaço da obra em local de produção in loco de componentes, em local de armazenamento, em local de instalação de equipamentos de obra e em setor administrativo, além do espaço para abrigar os trabalhadores. Mantém-se a indefinição de espaços públicos x privado ( canteiro de obras) e há o trânsito irrestrito de pessoal dentro do espaço de produção do edifício. Ainda há construção aleatória das instalações de apoio à obra (sanitários, refeitório, escritório, central de produções, etc), sem um padrão orientativo ou definição de condições mínimas de salubridade. A técnica construtiva estava em transição da artesanal e de fácil manuseio (madeira, blocos cerâmicos, roldanas) para a industrialização de componentes e uso de maquinários de grande porte (ex.:guindaste).

Sobre as relações de vizinhança do canteiro de obras, neste objeto de estudo, a peculiaridade é que a vizinhança do canteiro de obras é o cerrado - a natureza intocada do interior do Brasil, em que a tamanha extração de madeiras para a obra gerou polêmicas ambientais. A imensa oferta de mão obra, adulta e infantil, foi absorvida em várias tarefas da obra, de modo informal e formal, com jornadas intensas e excessivas e com muitos acidentes de trabalho.

Quanto aos impactos urbanos do canteiro de obras, o aspecto de interiorização no território emerge a ausência de infraestrutura de saúde, indústrias, comércio, lazer, sistemas de transporte. A partir dessa lacuna, os próprios operários e familiares iniciaram suas atividades produtivas para suprir essa demanda local. Assim, dando início a centralidades e pontos de referência naquele arranjo urbano secundário à obra de Brasília. Destes arranjos, constituíram-se vila de operários e sua crescente organização urbana, de caráter informal, rumou para a organização de cidades, conhecidas como cidades satélites de Brasília.

\subsection{DÉCADA DE 1970: DEMANDA POR REQUISITOS PARA QUALIFICAR AS CONDIÇÕES DE TRABALHO EM CANTEIROS DE OBRAS}

O projeto do conjunto habitacional da Quinta da Malagueira, de Álvaro Siza, em Évora/Portugal é cenário para a abordagem das novas diretrizes para a qualidade do trabalho no espaço de produção da obra. Há registos oficiais sobre a organização espacial do canteiro de obras, devido a crescente política de demanda por higiene, saúde e segurança do trabalho por parte governamental e de sindicatos da categoria (Decretolei n.. 41.820/1958; Decreto no 46427/1965). Ver imagem 2 e 7. 
A organização espacial do canteiro de obras ainda é inicial de modo a prever local de produção in loco de componentes, em local de armazenamento, em local de instalação de equipamentos de obra e setor administrativo. Em alguns casos, ainda mantém-se a indefinição de espaços públicos $x$ privado ( canteiro de obras), há o trânsito irrestrito de pessoal dentro do espaço de produção do edifício. A construção das instalações de apoio à obra (sanitários, refeitório, escritório, central de produções, etc) segue um padrão orientativo de condições mínimas de salubridade. A técnica construtiva em transição da artesanal e de fácil manuseio (madeira, blocos cerâmicos, roldanas) para a industrialização de componentes e uso de maquinários de grande porte (ex.:guindaste)

\subsection{DÉCADA DE 1980: NORMATIZAÇÃO DE REQUISITOS PARA O CANTEIRO DE OBRAS}

As intervenções habitacionais no bairro de Grácia da cidade de Barcelona/Espanha, em meio ao contexto do grande centro urbano, necessitou de ordenação nas questões de execução de obras civis. Assim, o Real Decreto 555/1986 de 21 de fevereiro, tratou sobre a inclusão obrigatória de um estudo de Segurança e Saúde no Trabalho, em projetos de construção e obras públicas. A parti dele, a organização espacial do canteiro de obras também deve orientar-se pelo ambiente de trabalho seguro nas obras de construções civis. Era necessário desenvolver um Estudo Documentado sobre o espaço da obra e elaborado pela empresa construtora, considerando:

a) relatório descritivo e os procedimentos técnicos a utilizar, considerando risco relativo de acidentes de trabalho e doenças e especificação de medidas preventivas;

b) condições especiais da legislação aplicáveis às características do trabalho;

c) planejamento da execução das medidas preventivas definidas no relatório;

d) acompanhamento contínuo da implantação dos elementos de segurança e saúde no trabalho que foram definidos ou projetadas.

e) orçamento, que quantifica a despesas totais previstas para a implementação e execução do estudo Saúde e Segurança.

Deste modo, verifica-se que o resultado da aplicação do Real Decreto é a definição clara entre espaço público e privado em obra, acentua o controle produtivo e operacional em obra, possibilita um padrão de organização no arranjo físico do canteiro de obras, associando o Real Decreto e a logística de produtividade da empresa( espaços de apoio e de produção), e a aplicação de diferentes tecnologias construtivas nos ambientes do canteiro de obras (ex.: conteiner.), no intuito de racionalizar custos e com foco na sustentabilidade dos componentes. As relações de vizinhança do canteiro de obras eram realizadas em meio à malha urbana já constituída e em plena atividade, logo era necessário seguir as orientações normativas (sobre horário de trabalho, carga e descarga, circulação de veículos pesados, controle de resíduos, ruídos,etc). Ainda, a relação de vizinhança era próxima com alguns morados vizinhos ao terreno da intervenção, havendo um constante olhar de vigília e acompanhamento sobre a obra. Ver imagem 2 e 7.

Pode-se verificar que o impactos urbanos do canteiro de obras a época eram público operariado das obras intensifica a circulação de veículos (caminhão, ônibus, carros, moto, bicicleta) nas ruas próximas, as condições ambientais alteradas pelo ruído e poeiras das atividades da construção civil, além de alterações de trajeto de vias ou passeios públicos para servirem de apoio às atividades da obra (carga e descarga).

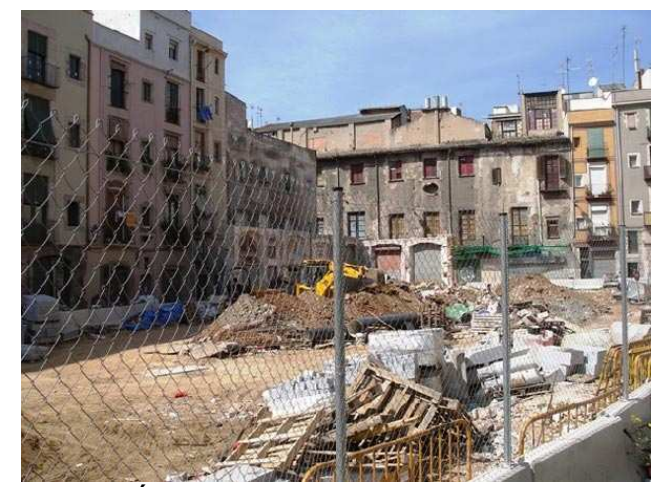

Imagem 6: Área de intervenção no bairro de Gràcia em Barcelona para a reorganização da qualidade ambiental no quarteirão do centro urbano nos anos de 1980/1990. Fonte: Foto de Horacio Capel

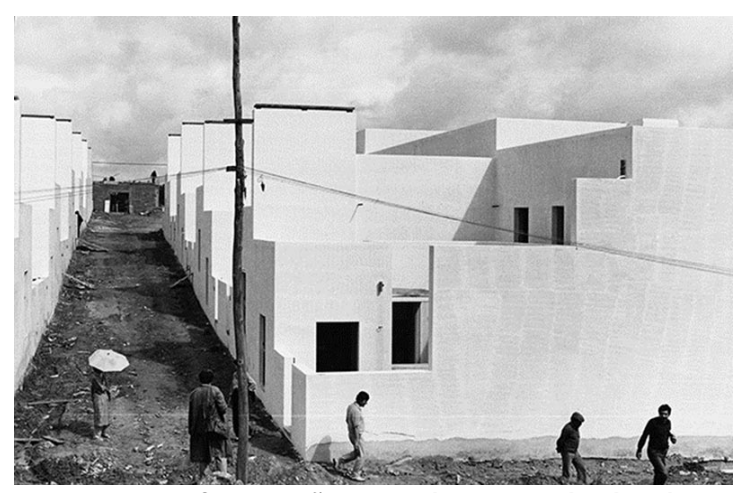

Imagem 7: Construção das unidades habitacionais da Malagueira em, Évora no final dos anos de 1970. Fonte: http://socks-studio.com/2016/05/13/quinta-damalagueira-in-evora-by-alvaro-siza-1977-1998/ 


\subsection{UMA CIDADE CANTEIRO DE OBRAS}

Há situações na construção civil em que o porte da obra a ser realizada e o significado local do canteiro de obras, no sentido da importância de sua estrutura urbana, podem influenciaram na transformação de um espaço provisório em vilas, bairros ou cidades, como ocorreu com as áreas do canteiro de obras dos candangos em Brasília/Brasil. Outra obra com tamanho impacto no arranjo produtivo local é o caso da construção da Usina Hidroelétrica de Belo Monte em Altamira, estado do Pará/Brasil, que envolve um canteiro de obras para aproximadamente 25 mil operários. Ver imagem 8.
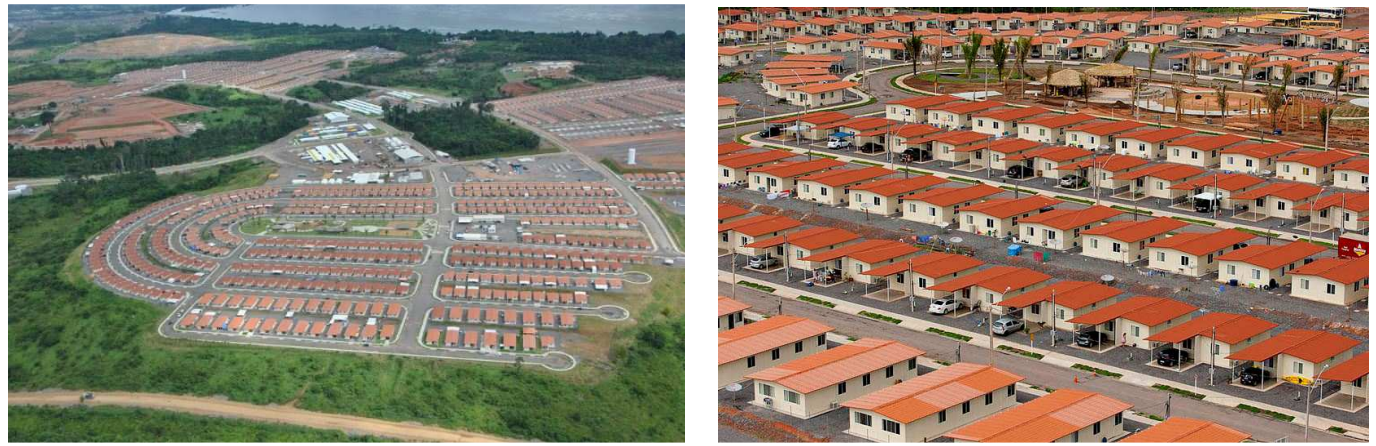

Imagem 8: Construção do canteiro de obras para abrigar os $25 \mathrm{mil} \mathrm{trabalhadores} \mathrm{da} \mathrm{Usina} \mathrm{de} \mathrm{Belo} \mathrm{Monte} \mathrm{em} \mathrm{Altamira/Pará.} \mathrm{À}$ esquerda, a vista aérea do canteiro de obras e à direita, o detalhe do espaço construído no local.

Fonte: http://www.pac.gov.br/mochilao/uhe-belo-monte-pa

Segundo dados do jornal Folha de São Paulo de 2013 em matéria especial, é a maior obra de engenharia em execução no Brasil e iniciou em 2011, sendo o planejamento do canteiro de obras baseado também nas diretrizes do Ministério do Trabalho e Emprego por meio da Norma Regulamentadora $n^{\circ} 18$, que dispõe sobre aspectos organizacionais, dimensionais e construtivos dos ambientes do canteiro de obras.

A partir das imagens do canteiro de obras da usina de Belo Monte, verifica-se que o local possui organização urbana com zoneamento de funções: moradia, lazer, circulação, serviços (saúde, administração). Há vias de circulação internas e passeio pavimentados, praça com equipamentos de lazer e variação tipológica da unidade habitacional para atender os diferentes perfis de trabalhadores (alojamento compartilhado, casa unifamiliar). A alimentação é fornecida pela emprega construtora em refeitório próprio e há um hospital com maternidade neste canteiro de obras, pois $51 \%$ dos trabalhadores é casado.

A instalação desse canteiro de obras, considerando o porte, a geografia, a política habitacional e a tecnologia construtiva, remete a um plano de expansão urbana para sanar demandas habitacionais ou um projeto de qualificação urbana da periferia urbana.

Um olhar arquitetônico na unidade habitacional do canteiro de obras de Altamira remete aos modelos da SIEDLUNG (casa unifamiliar com quintal),com diferenciação de tipologias e organização interna de equipamentos públicos (praça, cinema, hospital, refeitório,etc), sendo trabalhada a borda do conjunto de forma a delimitar e demarcar o espaço do canteiro de obras da empresa. Há uma clara definição entre o espaço público x privado, bem como a orientação das vias de acesso com diferenciação de larguras para referenciar as hierarquias. Ver imagem 9.

Pode ser compreendido como uma evolução do espaço do canteiro de obras da construção de Brasília, em que neste a auto-organização pelos candangos prevaleceu e trouxe relações complexas para a organização da urbanidade do local.

Iniciado nas SIEDLUNGs alemãs, outro aspecto presente massivamente em Altamira é a racionalização do projeto e do processo de construção dos espaços do canteiro de obras, de modo a ser uma premissa de projeto e não mais uma opção.

A cultura local também exerce influência na organização do espaço do canteiro de obras, assim como foi fator primordial o projeto da Malagueira. A escala (pequena), a topografia (segue o relevo) e a tipologia (com varanda) estão relacionadas com as casas existentes na cidade de Altamira.

E sendo uma obra realizada no interior de uma cidade pequena numa das regiões pouco povoadas do Brasil, há a aplicação da normativa específica para o espaço do canteiro de obras. Isso respalda a 
necessidade de instrumentos legais para promover a organização do espaço da obra e promover um ambiente digno e adequado ao trabalho e à moradia nos canteiros de obras, à luz dos exemplos das intervenções em grandes cidades, como Barcelona.

Após a finalização da obra, inicia-se a desmobilização (desmanche) do espaço do canteiro de obras, porém em obras de grande porte, como no caso de Altamira, o espaço do canteiro de obras permanece para a cidade, sendo incorporado como novo bairro. E no caso da construção de Brasília, o local do canteiro de obras se tornou uma nova cidade (Ex. Núcleo Bandeirante).
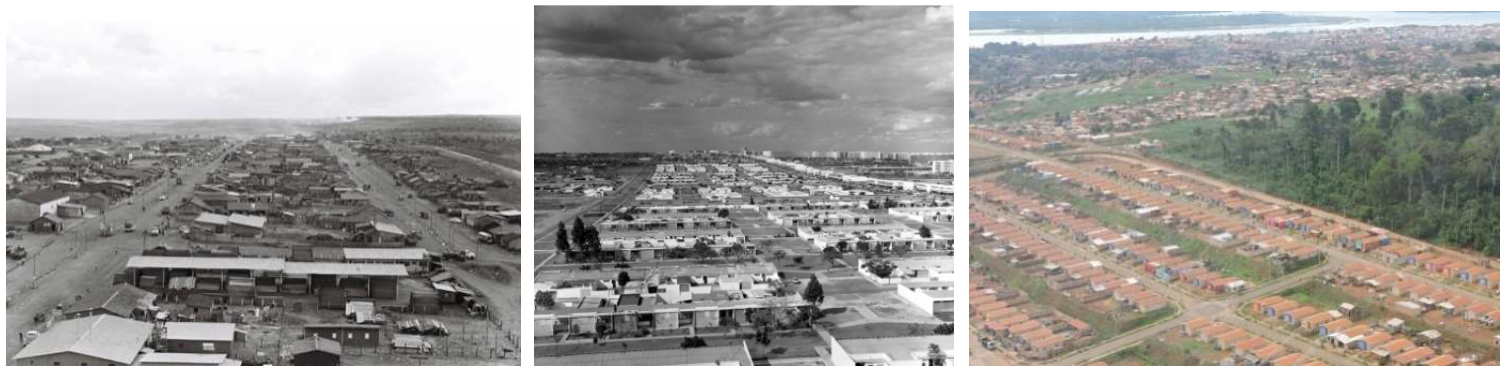

Imagem 9: A esq.-foto do canteiro de obras da construção de Brasília em 1960. Ao centro- foto da zona residencial da cidade de Brasília em construção. Á direita- foto do canteiro de obras da usina de Belo Monte e ao fundo a imagem da cidade de Altamira em 2013.

Fonte: Fotos de Brasília são do Arquivo Público do DF. Foto de Altamira:http://www.pac.gov.br/mochilao/uhe-belo-monte-pa

\section{CONCLUSÕES}

As transformações no modo de organizar as habitações nas cidades ao longo do século XX influenciaram o aspecto organizacional da cadeia produtiva da construção civil, especialmente na espacialização do canteiro de obras ao enfatizar a organização de funções, as etapas de implantação e relevância de planejamento prévio desse processo de produção da obra, conforme imagem 2.

O canteiro de obras saiu da informalidade das decisões aleatórias de campo para se instrumentalizar e se oficializar como uma etapa de projeto da edificação, elaborado pelos profissionais da área da construção civil, tendo reconhecimento técnico e normativo, fato que refletiu em uma nova tarefa remunerada.

Os reflexos sentidos na organização espacial do canteiro de obras se materializam em questões como a habitabilidade do espaço construído, a segurança do trabalho e a manutenção da urbanidade da cidade.

O canteiro de obras se origina do porte da obra a ser executada (pequena, média e grande) podendo assumir proporções de comunidade/vila a até cidade. Embora a legislação específica para essa etapa de obra limitar-se a apontar critérios mínimos de organização espacial, dimensionamento e aspectos de segurança do trabalho para a indústria da construção civil. 


\section{REFERÊNCIAS}

ASSOCIAÇÃO BRASILEIRA DE NORMAS TÉCNICAS(1991). NBR- 12284: Áreas de Vivência em Canteiros de Obras.

BONDUKI, N. G. (2002).Tendências e perspectivas na avaliação de políticas e programas sociais - uma metodologia para avaliar programas de habitação. IEE/PUC-SP.

DE SOUSA ARAÚJO, R.; JACYNTHO, T. I.(2014) Aspectos de qualidade e habitabilidade na comunidade Tamarindo. PerspectivasOnLine, v. 4, n. 16.

FERREIRA, E. A. M. (1998). Metodologia para elaboração do projeto de canteiro de obras de edifícios. Boletim Técnico da Escola Politécnica da Universidade de São Paulo. (Departamento de Engenharia de Construção, Civil BT/PCC/210)

MORENO, L. D.; MAMEDE, B. B.. (2014). Gestão da construção de edifícios no ambiente urbano: considerações sobre conseqüências e desdobramentos. Revista Nacional de Gerenciamento de Cidades, v. 1, n. 6.

SAURIN, T. A., FORMOSO, C. T.. (2006). Planejamento de canteiros de obra e gestão de processos. Recomendações Técnicas HABITARE, v. 3.

SILVA, H. N.(2014) Habitação em áreas de vivência e adequação de áreas de trabalho em três canteiros de obra em Criciúma -SC. Dissertação (Mestrado em Arquitetura e Urbanismo). Departamento de Arquitetura e Urbanismo da Universidade Federal de Santa Catarina, Florianópolis.

ZAPATEL, J. A. (2011). Barcelona: transformações urbanísticas (1979-1992)

ZAPATEL, J. A. (2013). Visões urbanas e habitação no século XX.

BRASIL.Portaria n 3.214 do Ministério do Trabalho e Emprego de 08 de junho de 1978. Institui as Normas Regulamentadoras no Brasil. Disponível em <http://trabalho.gov.br/images/Documentos/SST/NR/NR18/NR18atualizada2015.pdf (Consulta: 10/11/2016).

CAPEL, Horacio El debate sobre la construcción de la ciudad y el llamado "Modelo Barcelona". Scripta Nova. Revista Electrónica de Geografía y Ciencias sociales. Barcelona: Universidad deBarcelona, 15 de febrero de 2007, vol. XI, núm. 233. <http://www.ub.es/geocrit/sn/sn-233.htm>. (Consulta: 14/02/2017).

Jornal Folha de São Paulo. A Batalha de Belo Monte Disponível em http://arte.folha.uol.com.br/especiais/2013/12/16/belo-monte/index.html (Consulta em 13/02/2017) 